REVIEW ARTICLE

\title{
Translational evidence for lithium-induced brain plasticity and neuroprotection in the treatment of neuropsychiatric disorders
}

\author{
Stefano Puglisi-Allegra ${ }^{1 凶}$, Stefano Ruggieri ${ }^{1}$ and Francesco Fornai $\mathbb{B}^{1,2 \bowtie}$ \\ (c) The Author(s) 2021
}

Increasing evidence indicates lithium $\left(\mathrm{Li}^{+}\right)$efficacy in neuropsychiatry, pointing to overlapping mechanisms that occur within distinct neuronal populations. In fact, the same pathway depending on which circuitry operates may fall in the psychiatric and/ or neurological domains. $\mathrm{Li}^{+}$restores both neurotransmission and brain structure unveiling that psychiatric and neurological disorders share common dysfunctional molecular and morphological mechanisms, which may involve distinct brain circuitries. Here an overview is provided concerning the therapeutic/neuroprotective effects of $\mathrm{Li}^{+}$in different neuropsychiatric disorders to highlight common molecular mechanisms through which $\mathrm{Li}^{+}$produces its mood-stabilizing effects and to what extent these overlap with plasticity in distinct brain circuitries. $\mathrm{Li}^{+}$mood-stabilizing effects are evident in typical bipolar disorder (BD) characterized by a cyclic course of mania or hypomania followed by depressive episodes, while its efficacy is weaker in the opposite pattern. We focus here on neural adaptations that may underlie psychostimulant-induced psychotic development and to dissect, through the sensitization process, which features are shared in BD and other psychiatric disorders, including schizophrenia. The multiple functions of $\mathrm{Li}^{+}$highlighted here prove its exceptional pharmacology, which may help to elucidate its mechanisms of action. These may serve as a guide toward a multi-drug strategy. We propose that the onset of sensitization in a specific BD subtype may predict the therapeutic efficacy of $\mathrm{Li}^{+}$. This model may help to infer in BD which molecular mechanisms are relevant to the therapeutic efficacy of $\mathrm{Li}^{+}$.

Translational Psychiatry (2021)11:366; https://doi.org/10.1038/s41398-021-01492-7

\section{INTRODUCTION}

Lithium $\left(\mathrm{Li}^{+}\right)$remains the "gold standard" pharmacological agent for treating and preventing relapses in both type I and type II bipolar disorders (BDs). It is also effective in preventing suicidal behavior during major depression. Despite its strong efficacy, during the past years, $\mathrm{Li}^{+}$was less and less administered due to toxicity and the need of monitoring serum concentrations to strictly maintain safe therapeutic doses [1-5]. However, alternative methods to administer low but effective therapeutic $\mathrm{Li}^{+}$doses have been developed [6]. Besides its efficacy in treating and preventing symptoms of psychiatric disorders, $\mathrm{Li}^{+}$produces neuroprotective effects on a wide range of neuronal populations that are involved in both behavioral and motor-related circuitries.

In fact, increasing evidence is under debate, indicating $\mathrm{Li}^{+}$ efficacy in neurodegenerative disorders, pointing to common intracellular mechanisms, which occur within distinct neuronal populations. This is the case of Alzheimer's disease (AD), amyotrophic lateral sclerosis/frontotemporal dementia (ALS/FTD), and Parkinson's disease (PD) [4, 7].

Knowledge of these mechanisms may shed light on the pathogenesis and neuropathology of different psychiatric and neurological disorders. The molecular mechanisms of action of $\mathrm{Li}^{+}$ involve classic pharmacologic targets, such as cell surface receptors or modulation of neurotransmitters, second messenger systems, enzyme cascades, and transcriptional factors [1,8].
Here an overview is provided concerning the therapeuti $\mathrm{c} /$ neuroprotective effects of $\mathrm{Li}^{+}$in different neuropsychiatric disorders to highlight common molecular mechanisms through which $\mathrm{Li}^{+}$produces its mood-stabilizing effects and to what extent this overlaps with neuroprotection in various brain circuitries. In fact, similar cell alterations depending on which circuits take place may fall either in the psychiatric and/or neurological domains.

\section{GENERAL OVERVIEW OF MOLECULAR MECHANISMS OF LI ${ }^{+}$}

Some effects of $\mathrm{Li}^{+}$are related to the physical-chemical reversible competition with magnesium ion $\left(\mathrm{Mg}^{+}\right)$within specific catalytic protein domains involved in substrate phosphorylation. Evidence shows $\mathrm{Li}^{+\prime} \mathrm{s}$ ability to inhibit $\mathrm{Mg}^{+}$-dependent enzymes by displacing $\mathrm{Mg2}^{+}$from its binding sites, thereby reducing enzyme stability and activity [9]. Thus, pharmacological actions of $\mathrm{Li}^{+}$ mostly depend on the reciprocal $\mathrm{Li}^{+} / \mathrm{Mg}^{+}$ratio [10]. These mechanisms of action add on the multifaceted pharmacology of $\mathrm{Li}^{+}$[11], as well as its multiple targets.

The binding competition between $\mathrm{Li}+$ and $\mathrm{Mg} 2+$ at substrate enzyme sites modulates the activity of several enzymes within intracellular pathways involved in biochemical effects, which are relevant both for neuropsychiatric and neurodegenerative disorders. These include inositol monophosphatase (IMPase), Akt/

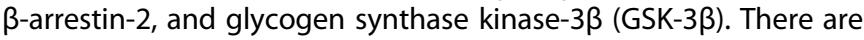

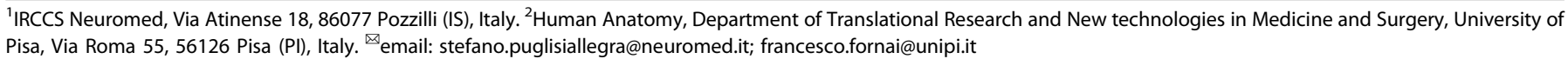

Received: 18 December 2020 Revised: 16 June 2021 Accepted: 23 June 2021

Published online: 05 July 2021 


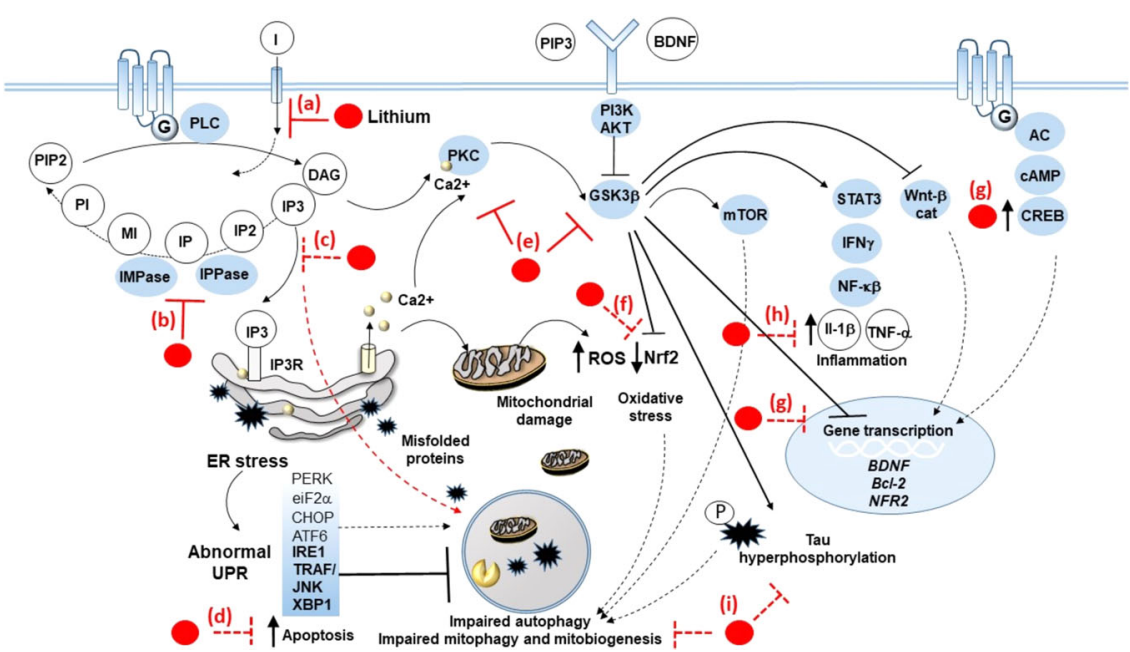

Fig. 1 Detailed drawing of the fine molecular mechanisms of lithium on specific cell targets. Lithium inhibits the PI cycle, which is activated following stimulation of G-coupled neurotransmitter receptors (GPCRs). PLC mediates the hydrolysis of phosphotidylinositol 4,5-bisphosphate $\left(\mathrm{PIP}_{2}\right)$ to the secondary messengers diacylglycerol $(\mathrm{DAG})$ and inositol trisphosphate $\left(\mathrm{IP}_{3}\right)$, which in turn activate downstream signaling pathways, including protein kinase $C(P K C)$, and $I P_{3}$ receptor $\left(I_{3} R\right) / E R$ stress/unfolded protein response (UPR). In detail, lithium inhibits (a) the reuptake of inositol (I), as well as IMPase and IPPase (b), which results in overall depletion of $\mathrm{IP}_{3}$ (c). In this way, lithium prevents autophagy impairment and apoptosis that are bound to $I_{3} R$-related ER stress, massive $\mathrm{Ca}^{2+}$ release from the ER, abnormal UPR, as well as the accumulation of misfolded/unfolded proteins and damaged mitochondria (d). Abnormal UPR consists, for instance, of upregulation of TRAF/ JNK and XBP1, which fosters apoptotic events while impairing autophagy. At the same time, through inhibition of PKC and GSK3 $\beta$ (e), lithium inhibits potentially deleterious effects triggered downstream of these pathways. These include (f) oxidative stress due to accumulation of reactive oxygen species (ROS) leaked from damaged mitochondria and downregulation of the nuclear factor erythroid 2 (NFE2)-related factor 2 (NRF2), which, besides its antioxidant effects, is also related to mitophagy and mitochondriogenesis; (g) impaired transcription of neurotrophic, neuroprotective, and antioxidant genes, such as BDNF, VEFG, Bcl-2, and NRF2, which is instead reinstated by lithium via both GSK3 $\beta$ inhibition and activation of the CREB transcription factor placed downstream of GPCRs; (h) production of pro-inflammatory cytokines underlying activation of the STAT/interferon gamma (INF $\gamma$ )/nuclear factor kappa-light-chain enhancer of activated B cells (NF-k $\beta$ ) pathway; and (i) accumulation of hyperphosphorylated tau, which is bound to cytoskeletal alterations and autophagy impairment.

two closely related forms of GSK-3, termed alpha (GSK-3a) and beta (GSK-3 $\beta$ ), which are equivalently inhibited by $\mathrm{Li}^{+}[12] . \mathrm{Li}^{+}$ inhibits GSK-3 by competing with $\mathrm{Mg}^{2+}$ for an essential binding site [13]. In addition to $\mathrm{Mg}^{2+}$ competition, $\mathrm{Li}^{+}$inhibits GSK-3 $\beta$ activity by increasing its phosphorylation [14]. $\mathrm{Li}^{+}$also decreases GSK-3 $\beta$ levels by inhibiting its transcription [15]. It is worth noting that, of all the kinases, GSK-3 influences the largest number of substrates [16]. Thus, $\mathrm{Li}^{+}$has been estimated to act at several hundreds of GSK3-dependent substrates through the modulation of a number of GSK-3-dependent pathways. Since $\mathrm{Li}^{+}$affects other $\mathrm{Mg}^{2+}$-dependent proteins, the occurrence of $>3000$ human proteins has been estimated that can be affected by $\mathrm{Li}^{+}$[17]. This ability to act on a plethora of molecules, each one owning a functional relevance, makes $\mathrm{Li}^{+}$a powerful pharmacological agent and a valuable tool in clinical and preclinical research.

During the past decades, evidence is provided showing that $\mathrm{Li}^{+}$ inhibits a number of phosphatases by acting as an uncompetitive and non-competitive inhibitor. Although the mechanisms of $\mathrm{Li}^{+}$-induced phosphatase inhibition are still not completely unveiled [18, 19], uncompetitive inhibition of IMPase and inositol polyphosphate 1-phosphatase (IPPase) has been recently proposed $[19,20]$. Inhibition of IMPase and IPPase markedly reduces inositol triphosphate (IP3) levels, which in turn modulate many intracellular pathways known to be relevant for both neuropsychiatric and degenerative disorders, such as autophagy [1].

A number of neurotransmitters including dopamine (DA), norepinephrine, and serotonin act through $G$ protein coupled receptors. Thus, the effects of $\mathrm{Li}^{+}$on the inositol cycle may translate into altered receptor activity following monoamine stimulation, which in turn may dampen neurotransmitter efficacy, thus inducing synaptic stabilization [10].

Remarkably, $\mathrm{Li}^{+}$also stimulates gene expression including brain-derived neurotrophic factor (BDNF) and vascular endothelial growth factor (VEGF). Low levels of BDNF during depressive, and manic phases in bipolar patients [21], have been reported to be reversed by $\mathrm{Li}^{+}$treatment. In line with this, $\mathrm{Li}^{+}$and BDNF plasma levels are inter-related [22]. $\mathrm{Li}^{+}$also regulates inflammatory processes blunting the pro-inflammatory response. In detail, it decreases lipopolysaccharide-induced inflammation in glial cells [23] and reduces the production of interleukin-1 beta and tumor necrosis factor-alpha. The ability of $\mathrm{Li}^{+}$to modulate inflammation is relevant to its pharmacological effects since the inflammatory processes play a crucial role both in neurodegeneration and mood disorders $[24,25]$.

$\mathrm{Li}^{+}$targets unfolded protein response (UPR)-related events, such as endoplasmic reticulum (ER) stress, excitotoxicity, and autophagy dysfunction either at the synapses or within cell bodies. This is expected to induce neuroplasticity, which affects behavior and motor activity, through overlapping mechanisms in different brain areas (Fig. 1).

UPR activation induces autophagy [26, 27], which counteracts ER stress via degradation of protein aggregates and organelles, including damaged mitochondria, nuclear membrane, and ER. Moreover, $\mathrm{Li}^{+}$rescues autophagy failure, which is often reported in neurodegenerative disorders, including $P D, A D$, tauopathies, ALS, and Huntington disease [7, 12, 25, 28-42]. Similarly, autophagy is often reported to be dysregulated in a number of psychiatric disorders.

Autophagy is a phylogenetically conserved eukaryotic cellclearing system that plays a seminal role in cell homeostasis [36]. It is distinguished into macro-autophagy, micro-autophagy, and chaperone-mediated autophagy, which all promote lysosomedependent substrate degradation [37]. Autophagy can be induced by a number of cascades, among which the one controlled by the mammalian target of rapamycin complex 1 (mTORC1) plays a relevant role. The mTOR complex represents a 
downstream substrate of the phosphoinositide-3 kinase/phosphatase and tensin homolog/Akt pathway.

Activation of $5^{\prime}$ AMP-activated protein kinase and inhibition of GSK3- $\beta[8,41]$ are other well-known pathways controlling autophagy initiation.

Besides degrading oxidized/misfolded proteins and damaged organelles, autophagy modulates key cell functions ranging from neural tube and synapse development to neurotransmitter release and synaptic plasticity, as well as neuroinflammation and immunity $[4,43]$.

Although $\mathrm{Li}^{+}$inhibits GSK-3 $\beta$, which reduces autophagy via mTOR activation, the prevalent effect of $\mathrm{Li}^{+}$consists in mTORindependent autophagy activation since $\mathrm{Li}^{+}$strongly inhibits IMPase [7, 44]. In line with this, inositol depletion has moodstabilizing effects $[1,42]$, while in tauopathies $\mathrm{Li}^{+}$may play a dual protective role by inhibiting GSK-3 $\beta$ [45], producing strong autophagy-independent neuroprotective effects and counteracting tau accumulation through autophagy activation ([46], Fig. 1).

Autophagy activation is expected to clear damaged mitochondria (mitophagy), and by a concomitant increase in mitochondriogenesis, this speeds up mitochondrial turnover, which improves mitochondrial function. $\mathrm{Li}^{+}$-induced mitochondriogenesis and mitophagy occur both in endothelial cells [47] and specifically within various neuronal types [27, 34].

Such an effect, which is overtly crucial in neurodegeneration, also applies to mood disorders since mitochondrial dysfunction is reported in bipolar patients $[48,49]$.

Thus, even considering $\mathrm{Li}+$ strong therapeutic effects on mood disorders, it is likely that autophagy takes a center stage in its antimanic and antidepressant action. This is not surprising when considering that a number of autophagy-inducing drugs, which are on-label with other therapeutic indications, possess moodstabilizing effects (i.e., valproate, rapamycin, [46]). Similarly, the specific efficacy on mood disorders of a variety of psychotropic drugs may partly relate to autophagy-inducing effects [50-52].

\section{LITHIUM IN NEURODEGENERATIVE AND PSYCHIATRIC DISORDERS \\ Neurodegenerative disorders: AD and PD and ALS/FTD}

A growing body of evidence points to the neuroprotective effects of $\mathrm{Li}^{+}$. Subjects with $\mathrm{BD}$ administered with long-term $\mathrm{Li}^{+}$have a lower risk to develop dementia including $A D$ [53, 54]. A metaanalysis study [55] shows that $\mathrm{Li}^{+}$treatment significantly decreases cognitive decline as compared with placebo, thus indicating that $\mathrm{Li}^{+}$may be beneficial in promoting cognitive performance in subjects with mild cognitive impairment $(\mathrm{MCl})$ and AD.

$\mathrm{Li}^{+}$may act at multiple steps within the biochemical cascades involved in the onset and progression of AD (Fig. 1). For instance, GSK-3 $\beta$ inhibition may counteract the pathological increased enzyme activity occurring in patients affected by $\mathrm{MCl}$ and $\mathrm{AD}$ [56]. GSK-3 $\beta$ is involved in amyloidogenesis and tau phosphorylation, which at the preclinical level are inhibited by $\mathrm{Li}^{+}$administration [57]. Again, $\mathrm{Li}^{+}$-induced autophagy may counteract autophagy suppression, which is expected in $A D$ patients due to a progressive increase in mTOR activity during the disease course $[35,58]$. Moreover, $\mathrm{Li}^{+}$promotes the synthesis and release of neurotrophic factors, in particular BDNF and VEGF whose increased availability protects neurons against neurotoxic insults, stimulates hippocampal neurogenesis, and increases synaptic plasticity [2]. Indeed, BDNF polymorphisms were reported to moderate $A \beta$-related cognitive decline in preclinical $A D$ [59], and BDNF reduces $A \beta$ in the brain [60]. However, a short half-life and inability to cross the blood-brain barrier impair the therapeutic potential of BDNF [61].

Such a limitation is overcome by small molecules like BDNF mimetic compounds that are able to protect primary neurons from $A \beta$-induced toxicity and to promote synaptogenesis [62]. Moreover, $\mathrm{Li}^{+}$is able to effectively activate the molecular pathway increasing BDNF synthesis [10] It is worth noting that animal models play a key role in $A D$ research also fostering clinical studies in patients to assess $\mathrm{Li}^{+}$efficacy in contrasting $A \beta$ and tau pathology [63].

ALS is a motor neuron disease, belonging to a group of neurological disorders that selectively affect motor neurons controlling voluntary muscles of the body. ALS can be classified as familial or sporadic, depending on whether or not there is a family history of the disease. Although there is no consensus on the familial definition, a number of genes are considered to cause the disease.

Motor symptoms improvement by $\mathrm{Li}+$ was reported during the past two decades. Thus, in a clinical trial, $\mathrm{Li}^{+}$treatment for 15 months was shown to be safe and significantly associated with a slower rate of disease progression and death [28]. Substantial neuroprotection accompanied by delayed disease onset and increased life span was shown in G93A murine model [28]. It should be pointed out that several ALS genetic murine models have been developed [64]. Although of huge utility in preclinical research, they are partially representative of the pathology and the efficacy of lithium in these models deserves to be further investigated [65].

Daily doses of $\mathrm{Li}^{+}$, leading to plasma levels ranging from 0.4 to $0.8 \mathrm{mM}$, delay disease progression in a small group of ALS patients [28]. This was further validated in a stratified study on ALS patients carrying the UNC13A variant where $\mathrm{Li}^{+}$doubles survival time [29], while in a heterogeneous ALS population these protective effects of $\mathrm{Li}^{+}$are debatable. Thus, it is clear how $\mathrm{Li}^{+}$affects multiple targets, all of which are likely to contribute to the improvement of $\mathrm{ALS}$, such as autophagy that involves $\mathrm{Li}^{+}$inhibitory action on GSK3 and $\mathrm{IP}_{3}$ turnover or suppression of glial cell activation in the spinal cord [4].

$\mathrm{Li}^{+}$induces autophagy to counteract ER stress and altered UPR and rescues autophagy failure occurring in both ALS/FTD and BD $[7,28,34,35,49,66-72]$. Noteworthy, UPR markers (p-elF2a, GRP78, GRP94, XBP1, and CHOP) have been shown to predict $\mathrm{Li}^{+}$ responsiveness in bipolar patients [70].

$\mathrm{Li}^{+}$-responsive psychiatric disorders, such as BD, depression, and anxiety, may often precede ALS/FTD, and patients with psychiatric disorders receiving regular $\mathrm{Li}^{+}$treatment have a reduced prevalence of ALS and dementia [73].

This evidence shows once more that neurodegenerative diseases and affective disorders may share common neural mechanisms into which $\mathrm{Li}^{+}$acts as therapeutic, strongly suggesting that these mechanisms are crucial in etiology.

$\mathrm{Li}^{+}$efficacy in PD has been poorly studied and results indicate that it deserves substantial clinical trials to ascertain promising neuroprotection as suggested by experimental models.

In a parkin mutant transgenic mouse, low doses of $\mathrm{Li}^{+}$prevent motor impairment as well as dopaminergic striatal degeneration, parkin-induced striatal astrogliosis, and microglial activation. These results further validate $\mathrm{Li}^{+}$as a potential therapy for PD [74]. At first glance, this may sound odd since $\mathrm{Li}^{+}$by impeding sensitization produced by DA [75] is expected to attenuate the efficacy of the long-term L-DOPA response, which represents an important part of L-DOPA symptomatic effect. Thus, a symptomatic interference of $\mathrm{Li}^{+}$with PD may hide the disease-modifying effect produced by $\mathrm{Li}^{+}$acting on autophagy-dependent ongoing degenerative steps $[7,69]$.

Alpha-synuclein, a major substrate of autophagy, accumulates in Lewy bodies, which are mostly found within spared dopaminergic neurons of the substantia nigra pars compacta [76], as well as within extra-nigral neuronal populations [77].

Moreover, genetic ablation of Atg7 specifically within DA neurons fully reproduces PD pathology, including the formation of alpha-synuclein-stained Lewy bodies. Evidence that points to a 
key role of autophagy in DA-related disorders [78] and $\mathrm{Li}^{+}$as a potential therapy for PD has been provided [4].

\section{Psychiatric disorders: BD, and major depressive disorder (MDD), and schizophrenia}

$\mathrm{Li}^{+}$mood-stabilizing effects are evident in typical BDs characterized by a cyclic course of mania or hypomania followed by depressive episodes, while efficacy is weaker in the opposite pattern [5]. In fact, $\mathrm{Li}^{+}$is less effective in bipolar depression, in rapid cycling, in psychotic syndromes, in drug abuse, and in depression-prone cases [5]. Moreover, the effects produced by $\mathrm{Li}^{+}$ in major depression are not as significant as those produced in cycling $\mathrm{BD}$, as we report briefly below.

$\mathrm{Li}^{+}$has been proposed for treating MDD since the last decades of the past century $[79,80]$ as an alternative pharmacotherapy for those patients who were refractory to antidepressants. At present, no clear evidence is available on the efficacy of $\mathrm{Li}^{+}$monotherapy compared either with placebo or antidepressants in acute, unipolar, major depressive episodes [78]. However, a number of studies have reported the beneficial effects of $\mathrm{Li}^{+}$, even when it is administered as an adjunct to antidepressant treatment [81, 82].

$\mathrm{Li}^{+}$has been consistently reported to be effective in reducing the suicide risk both in unipolar and bipolar patients [83], possibly acting on GABA [67] to modulate aggression and impulsivity [84-86] via autophagy [87].

$\mathrm{Li}^{+}$is not effective in schizophrenia, as documented by literature from the past decades (see [86] for a review). Albeit $\mathrm{Li}^{+}$is co-administered with specific antipsychotics to relieve some side effects, this does not imply any efficacy of $\mathrm{Li}^{+}$to treat schizophrenia [88, 89]. This may sound unexpected since schizophrenia and BD share some functional and symptomatic features. Indeed, this discrepancy in therapeutics confirms what was originally indicated by Emil Kraepelin who in 1899 distinguished "dementia praecox" (further called schizophrenia) from "manisch-depressive irreisen," "manic-depressive insanity," and manic-depressive disorder, nowadays named BD. Such a distinction is currently maintained despite some conflicting hypotheses [90].

We do not wish to deal with such a nosographic issue; we rather want to emphasize how the discrepant effects of $\mathrm{Li}^{+}$in these disorders may rely on distinct molecular mechanisms operating in schizophrenia compared with BDs, owing to distinct molecular targets.

This is a crucial point since schizophrenia and BD share some behavioral alterations and neurotransmitter changes (e.g., DA and glutamate). Moreover, genetic correlations and common genes between these disorders have been shown [91-93].

These similarities suggest that these disorders do possess some overlapping steps in their molecular mechanisms. However, the simple fact that $\mathrm{Li}^{+}$is poorly or no effective in schizophrenia urges to investigate which $\mathrm{Li}^{+}$-dependent or $\mathrm{Li}^{+}$-independent molecular pathways exist in BDs compared with schizophrenia, respectively $[94,95]$.

Why then $\mathrm{Li}+$ is effective in BD and possesses a poor efficacy if any, in schizophrenia? We will discuss such a difference by pointing out the cycling nature of $\mathrm{BD}$ in contrast with $\mathrm{a}$ progressive course of schizophrenia.

It is important to note that the molecular pathways that are implicated in the sensitization phenomenon are crucial in schizophrenia, in BD, as well as in psychotogenic effects of abused psychostimulants. In fact, the cycling nature of BD may be key in the specific pattern of sensitization, which develops in such a disorder, contrasting with a progressive course, which otherwise takes place in schizophrenia.

$\mathrm{Li}^{+}$is effective in suppressing or delaying psychostimulantinduced sensitization [96] by acting on some common mechanisms also shared by schizophrenia and BD.

Although both disorders share sensitization mechanisms, only BD is sensitive to $\mathrm{Li}^{+}$, which remains in search of an explanation.
We suggest that a sensitization process exists in both disorders although the time course of such a sensitization diverges, which explains the different outcome of a similar pharmacological manipulation.

Sensitization is a process through which repeated intermittent exposure to a given stimulus, such as stress, trauma, or psychostimulants, leads to enhanced behavioral responses to subsequent exposure [97-99].

The presence of behavioral sensitization in patients with BD has been proposed to explain relapses and the progression of behavioral dysfunction [97, 100].

The effects of psychostimulants are relevant to study the molecular mechanisms that operate in the sensitization process, which takes place in psychiatric disorders and is shared by schizophrenia and BD. In fact, when psychostimulants are chronically abused, psychotic or manic symptoms may occur, which further provides witness for a promiscuous overlap between molecular mechanisms operating in these disorders.

Therefore, we focus here on the effects of psychostimulants on neural adaptations underlying drug abuse and psychotic development, to highlight, through the sensitization process, which features are shared or not between schizophrenia and BD.

\section{$\mathrm{Li}^{+}$, dopamine-related sensitization, and cell-clearing systems} Amphetamine (AMPH) repeated administration induces behavioral sensitization revealing a suited manic-like preclinical model [101-103]. Translational validity of sensitization to psychostimulant psychological stress [97, 104-106] is also supported by the overlapping of their neural effects, especially on dopaminergic transmission. This may also explain why AMPH induces manic symptoms in both healthy volunteers and BD subjects [107].

Chronic cocaine in preclinical model produces behavioral sensitization and decreases $\beta$-catenin levels in the prefrontal cortex, amygdala, and dorsal striatum. Accordingly, GSK-3 $\beta$ activity levels in these areas are increased [108]. $\mathrm{Li}^{+}$treatment rescues $\beta$-catenin levels and blocks cocaine-induced sensitization [108]. These results are consistent with $\mathrm{Li}^{+}$-induced GSK-3 $\beta$ inhibition and the following increase in $\beta$-catenin levels. However, contrasting results show increased $\beta$-catenin levels within nucleus accumbens that parallels the expression of cocaine sensitization, both phenomena being rescued by $\mathrm{Li}^{+}$administration [109, 110], thus casting a scenario in which $\mathrm{Li}+$ effects appear contradictory. Possible involvement of neurotransmitters has been advocated to explain these differences and a role of neural networks, in which reciprocal influences between brain areas may affect them differently [109].

Methamphetamine (METH), as well as other psychostimulants, commonly produces psychoses with positive symptoms similar to those of schizophrenia. Such an effect makes METH use/abuse to be commonly considered as an experimental model of schizophrenia. High pre-synaptic DA synthesis and release are peculiar of schizophrenia [111-113]; likewise, the psychostimulant effects of METH rely on increased DA synthesis and massive DA release within limbic and dorsal striatal areas, as well as abnormal stimulation of postsynaptic DA receptors (DARs), mainly the D1 subtype (D1Rs) [114, 115]. On the other hand, schizophrenic patients are oversensitive and overresponsive to AMPHs $[98,111]$.

METH dysregulates a number of susceptibility genes for schizophrenia, such as DISC1, NRG1/ErbB4, and CRMP2, which are known to be involved in the regulation of presynaptic DA release or post synaptic D1R-related cascades. Noteworthy, they all converge on mTOR signaling, thus abnormal stimulation of D1Rs activates significantly mTOR, which inhibits the autophagy machinery [116]. This suggests that altered mTOR and impaired autophagy pathway represent a common hub between psychostimulant-induced neuroplasticity and schizophrenia.

METH impairs the ubiquitin proteasome system (UPS) activity, which is largely dependent on DA [117-122]. Proteasome 


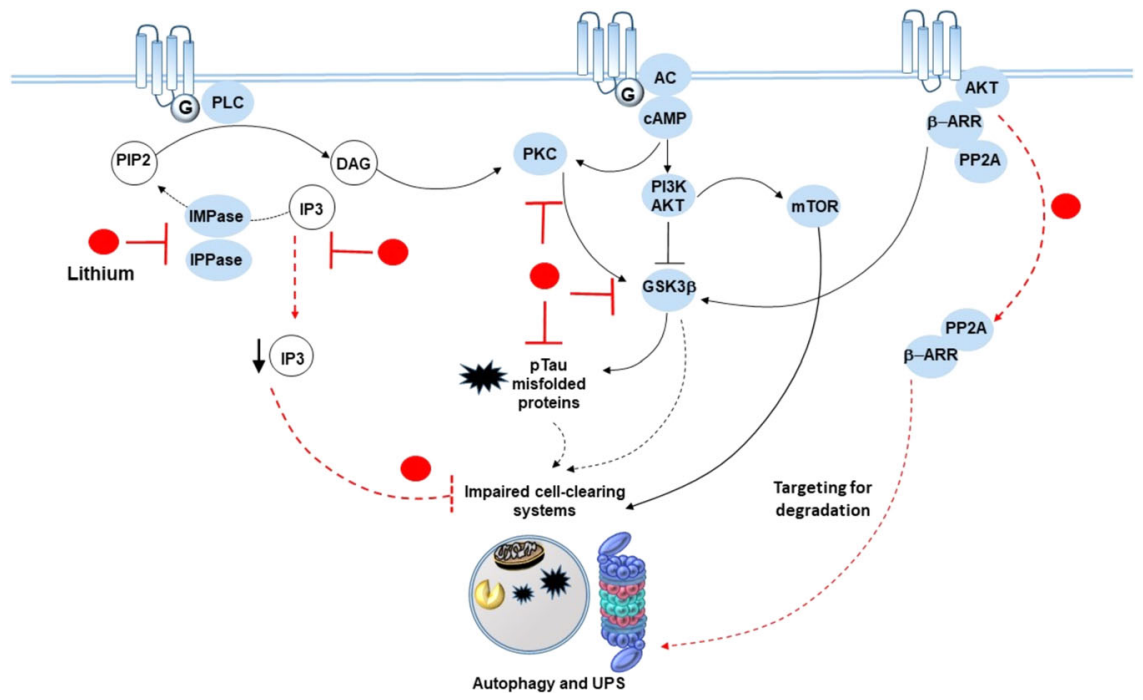

Fig. 2 Lithium, amphetamine-related sensitization, and cell-clearing systems. Lithium inhibits IMPase and IPPase, as well as PKC and GSK3 $\beta$, which are triggered downstream of dopamine GPCRs. This results in reduced production and phospho-tau/misfolded proteins and the rescue of cell-clearing systems, which are impaired by mTOR hyperactivation placed downstream of D1 DA receptors and/or by abnormal amounts of phospho-tau. At the same time, lithium disassembles the GSK3- $\beta$-activating proteins $\beta$-ARR and PP2A from the complex they form with GPCRs/AKT meanwhile targeting them for degradation by the cell-clearing systems. In this way, lithium adjusts dopamine imbalances that occur following psychostimulant intake/administration and abnormal activation of GPCRs and related downstream signaling pathways.

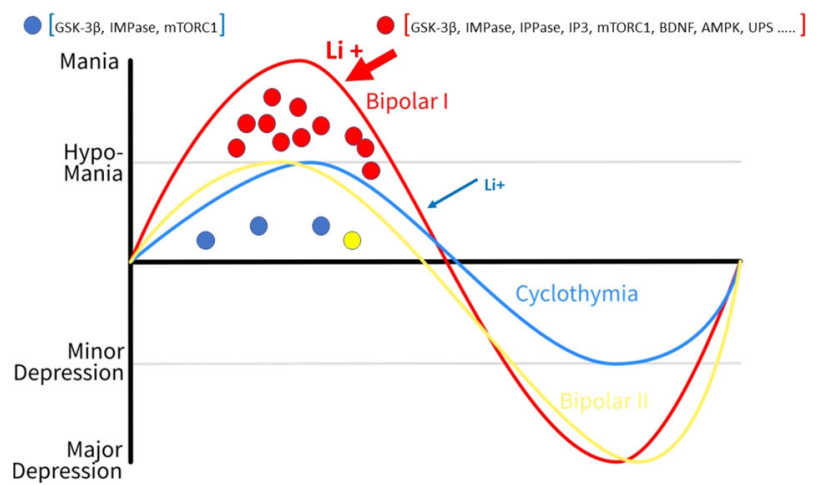

Fig. 3 Neural molecular substrates of lithium determining its differential affinity and efficacy for BD1 vs BD2. Circles represent neural molecular substrates of $\mathrm{Li}^{+}$. Red circles represent the most abundant neural targets of $\mathrm{Li}^{+}$underlying its therapeutic efficacy in mania (BD1); blue and yellow circles indicate a progressively

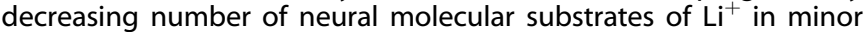
and major depressive disorders (cyclothymia and BD2).

regulates DA presynaptic release and receptors and postsynaptic DARs. Activation of DAD2 receptor subtype (D2Rs) contributes to the expression of DA-dependent METH-induced behavioral alterations also via a signaling complex composed of $\beta$-arrestin 2 ( $\beta$-arr2), AKT, and protein phosphatase-2A (PP2A), which activates GSK-3 $\beta$ [123-126].

$\mathrm{Li}^{+}$is a direct inhibitor of GSK-3 and also inhibits GSK-3 activity in the cell through an indirect mechanism that involves Akt activation. $\mathrm{Li}^{+\prime} \mathrm{s}$ ability to disrupt $\beta$-arr2-mediated Akt/GSK3 signaling contributes to suppressing the behavioral effects of enhanced DA transmission (Fig. 2, [123-127]).

D2Rs activate a signaling complex composed of $\beta$-arr 2 , Akt, and PP2A, which activates GSK-3 $\beta[123-126,128,129]$ and fosters DAdependent behavioral changes induced by METH. $\mathrm{Li}^{+}$antagonizes DA-related behavioral sensitization through inhibition of GSK-3 $\beta$ (Fig. 2, [123-127]). All components of the complex that activates GSK3 $\beta$, including $\beta$-arr $2, A K T$, and PP $2 A$, are UPS substrates, whose inhibition, similarly to METH and DA, activates GSK-3 $\beta$, while, conversely, GSK-3 $\beta$ inhibition protects from UPS inhibitioninduced toxicity (see [122] for a review).

Furthermore, $\mathrm{Li}^{+}$can blunt DA transmission through $\mathrm{IP}_{3}$ and protein kinase $C$ (PKC) placed downstream of DA1Rs or D1/D2 heterodimers [130, 131].

Based on this body of evidence we suggest that the occurrence of sensitization in a subtype of $B D$ may be relevant to the therapeutic outcome of $\mathrm{Li}^{+}$in the very same BD phenotype. This may allow inferring on which molecular mechanisms are relevant to the therapeutic effects of lithium in BD.

$\mathrm{Li}^{+}$is notoriously highly effective in BD1 compared to the hypomanic phase that characterizes the type 2 disorder (BD2). Although the usefulness of such a distinction between BD1 and BD2 is not unanimously shared [132], it represents an important element for understanding the action of $\mathrm{Li}^{+}$, together with blunted $\mathrm{Li}^{+}$efficacy on BD depression compared with mania.

Evidence for $\mathrm{Li}^{+}$therapeutic efficacy in BD1 clearly indicates that its action is intimately linked to the peculiar feature of the disorder, namely cyclicity. In fact, it is legitimate to infer that during the phase in which mania progressively rises ("mania rising"), as expressed by behavioral phenotype, $\mathrm{Li}^{+}$has a sort of higher "affinity" [133] for neural events spurring the "manic rise."

The factors implicated in this affinity should be sought in the "dynamic" status of systems where a number of molecular machineries would be "on fire" up to the peak. In fact, the syndrome "evolves" progressively towards the full expression of the manic phase (Fig. 3). The molecular factors of this "dynamic" condition are a serious candidate to unveil which mechanisms allow lithium to be most effective in this phase of BD1.

As reported above, sensitization is driven by molecular pathways linked to DA transmission, which owns a crucial role in BD [134]. Brain DA during the "mania rising" phase is dramatic and produces sensitization, as clearly indicated by behavioral, neural, and pharmacological evidence ([134], for review).

Importantly, sensitization progresses differently in different disorders. Thus, as evident also from behavioral changes, in BD1 the peak of mania is reached in the temporal order of weeks. Psychostimulant-induced sensitization falls into a similar (even shorter) temporal window. In schizophrenia, the process, also 
referred to as endogenous sensitization [135], develops over a longer period.

In each disease, two stages can be distinguished during the progression: one leads to a change in neural activity up to "peak," while the other stabilizes a steady state of modified activity once the peak is over. In fact, in BD, the mania phase recovers toward an adjustment that leads to a subsequent phase (euthymia or depression). Molecular mechanisms are mostly overlapping in these three disease conditions; however, since they do occur according to a different time course, they are likely to engage diverse and specific molecular pathways. Such a different progression may explain the contingent efficacy of $\mathrm{Li}^{+}$based on the time window when it is administered.

On the sidelines, let us consider briefly that once the manic phase is over some of the molecular pathways involved in "mania rising" are also involved in the phase of depression [126], possibly to counterbalance the sensitization adjustments through reverse mechanisms. This may exceed the adjustment which is needed, thus producing an outcome, which is "opposite" to mania. It can be hypothesized that $\mathrm{Li}^{+{ }^{\prime}} \mathrm{s}$ action on these pathways antagonizes depressive mood; nonetheless, the biological substrate to which $\mathrm{Li}^{+}$binds is not abundant enough to allow stochastic $\mathrm{Li}^{+}$binding to be adequate in a short time interval. This would not allow $\mathrm{Li}^{+}$to fully express its pharmacological activity. This view is supported by preclinical evidence showing that AMPH withdrawal after a repeated administration induces depressive-like behaviors $[99,136]$. However, $\mathrm{Li}^{+}$could maintain a blunted depressive mood by balancing neural mechanisms underlying motivational systems, which are regulated by DA transmission [106, 134, 137].

This progression brings to mind a sentence of an esteemed scholar of BD, Athanasios Koukopoulos, "Mania is the fire and depression its ash" $[138,139]$. This leads to consider a crucial effect of $\mathrm{Li}^{+}$action, namely the ability, once mania phase is over (corrected), to maintain a functional balance that leads to "stabilization."

It is important to consider that the therapeutic efficacy (although in a significant percentage of patients) is relevant in BD1, in many cases of psychostimulant sensitization, although it is practically absent in the case of schizophrenia, when its efficacy is minimal in rapid cycling and in BD2.

Major differences in sensitization between these disorders ground on time course and intensity (severity) of altered biochemistry, drug sensitivity, and disturbed behavior. The clearest differences in the time course occur between BD1 and schizophrenia as well as between slowly vs rapid-cycling BD1, while the most relevant difference in symptom intensity of the manic phenotype is between BD1 and BD2 or "mixed" states [140].

Importantly, a substantial increase in DA transmission following acute AMPH challenge was observed in patients with schizophrenia compared with healthy control subjects. These effects were evident in patients being at the onset of the disease and who were never previously exposed to neuroleptics or in patients experiencing an episode of illness exacerbation, but not during a remission phase [111]. This evidence indicates that DA hyperactivity is present in the schizophrenic patient at the onset of symptoms, in the relapse phases, and, possibly, during the prodromal period.

This suggests that marked $\mathrm{Li}^{+}$efficacy in BD1 is due to a massive DA activation, subsequent sensitization, and molecular mechanisms that are activated far in excess compared with other disorders. The molecular substrates activated by the DA overload could offer $\mathrm{Li}^{+}$a privileged "hooking" that would result in effective regulatory action and, in turn, effective therapy.

\section{DISCUSSION, LIMITATIONS, AND CONCLUSIONS}

In the present manuscript, we focused on the therapeutic effects of $\mathrm{Li}^{+}$to highlight common mechanisms of action in different neuropsychiatric disorders. These mechanisms provide valuable information to help to understand the etiology of disorders on which they are involved and point to possible therapeutic developments. $\mathrm{Li}^{+}$modulates a number of biochemical pathways in the brain involved in neuroplasticity and neuroprotection.

$\mathrm{Li}^{+}$neuroprotective action relies on the modulation of several intracellular pathways involved in ER stress, mitochondrial function, $\mathrm{Ca}^{2+}$ toxicity, UPR, and autophagy. The effects on the autophagy machinery remain the key molecular mechanisms to explain the protective effects of $\mathrm{Li}^{+}$for neurodegenerative diseases, which indicates how $\mathrm{Li}^{+}$exploits similar molecular machinery to modify the course of different disorders belonging to different domains.

Such molecular machinery may have a neuroprotective and neurotrophic action on AD and other degenerative dementias. In fact, upregulation of GSK-3 $\beta$ activity, which is inhibited by $\mathrm{Li}^{+}$, occurs in AD.

A failure of autophagy-dependent handling of misfolded proteins impedes the clearance of these substrates that accumulate within the cell. Therefore, a common pathogenesis underlying neurodegenerative disorders has been linked to autophagy inhibition due to mTOR activation. Common mechanisms are involved in $\mathrm{Li}^{+}$protective effects in neurodegenerative ALS/FTD disease as shown by significant improvement of motor function by treatment with $\mathrm{Li}^{+}$during the past two decades in clinical and preclinical studies.

$\mathrm{Li}^{+}$property to modulate autophagy offers potential therapeutic strategies for the treatment of neuropsychiatric disorders and emphasizes a crossroad linking autophagy, neurodegenerative disorders, and mood stabilization (antimanic activity). Remarkably, the molecular events in the progression of mania concern neuroplastic mechanisms implicated in neurotransmission as well as mechanisms of neurodegeneration.

Sensitization being a neuroplastic process that is crucial in the pathogenesis of main affective disorders, even slight differences in the sensitization process between these disorders may help to identify why some of them are sensitive to $\mathrm{Li}^{+}$, which is the case of BD1. Sensitization by psychostimulants is driven by molecular pathways linked to DA transmission and points to a number of mechanisms involved in psychopathology, most also crucial in neurodegenerative disorders.

$\mathrm{Li}^{+}$, as it is commonly acknowledged, has multifunctional power, in the sense that it impinges on different molecular pathways. In the case of the manic phase of BD1, the many pathways and the different mechanisms on which $\mathrm{Li}^{+}$acts can constitute a multifunctional complex fostering its activity (Fig. 1).

During "mania rising", sensitization at intracellular level recruits a number of molecular pathways that are matched by the same number of substrates binding $\mathrm{Li}^{+}$.

Sensitization process develops through dysregulation of various DAR subtypes, mainly D1, D2, and D3, at the presynaptic and/or postsynaptic level [126], including the involvement of the DA transporter. It should be borne in mind that, although the mesoaccumbens and meso-striatal pathways are markedly affected, cortical structures that regulate subcortical areas in integrated systems have a fundamental role. Thus, due to sensitization, monoaminergic systems in the medial prefrontal cortex undergo receptor or metabolic adaptations that are not paralleled by those taking place within subcortical areas [105, 106, 132, 141-143]. Therefore, molecular pathways implicated in network alterations are likely to provide further substrates for $\mathrm{Li}^{+}$efficacy.

Noteworthy, some apparent contradictory actions of $\mathrm{Li}^{+}$on molecular and/or system levels may witness a simultaneous activity on those different systems or subsystems [14, 144].

The unique therapeutic efficacy of $\mathrm{Li}^{+}$in mania may also be grounded on the ability of the ion to act on a wide number of molecular pathways and factors regulating neurotransmission [145], neuroplasticity, and neuroprotection. It can be assumed that 
functional alterations in "mania rising" bring into play molecular events on which $\mathrm{Li}^{+}$engages to counteract the move away from steady state (homeostasis). Noteworthy, $\mathrm{Li}^{+}$has been shown to be "attracted" from brain neurons of BD patients and not from those of healthy subjects [133], demonstrating an "affinity" of the ion for dysfunctional neural molecular substrates. This affinity can also be modulated by genetic factors that are obviously implicated in individual differences in therapeutic efficacy. In rapid-cycling disorders, the symptoms of the two states in short times rules out a cyclicity such that characterizing the progress of BD1. It is tempting to hypothesize that a lower efficacy of $\mathrm{Li}^{+}$in these disorders is due to a lack of cyclicity and a longer time course and more intense biochemical alterations. This sharply contrasts with what occurs in BD1, and it is supposed to prevent a substantial substrate being hooked by $\mathrm{Li}^{+}$for its effective therapeutic action.

The multiple functions of $\mathrm{Li}^{+}$prove its exceptional pharmacology, which may help to elucidate its mechanisms of action. $\mathrm{Li}^{+}$ actions may serve as a guide toward a multi-drug strategy and an improved development of a more effective therapeutic approach.

Our view is not devoid of limitations. We considered molecular mechanisms common to a number of disorders highlighting their role in neurodegeneration and neuroprotection, addressing autophagy machinery as a relevant mechanism for neural regulation and dysregulation in both neurodegenerative and psychiatric disorders. A potential limitation consists in the lack of a deep analysis on how all these mechanisms lead to neurodegeneration, in different neuronal populations within different brain areas. In fact, a sharp brain tissue alteration occurs in neurodegenerative disorders as well as in schizophrenia and BD [146].

Another limitation, inherently analyzed in the previous text, is the lack of an extensive analysis on diverse cell populations including various interactions between neural networks as well as neurons and glia [147, 148] These include a specific analysis of neurons hosted within specific brain areas being part of complex networks whose connections can favor or dampen neurodegenerative processes [131] Such a lack of diversified analysis may be crucial when referring to the sensitization process that takes a center stage in the scenario provided here. In fact, purposefully and maybe in a biased way, we focused on DA transmission dysregulation, which led to emphasize different types of DARs whose alteration can produce different effects depending on whether they are presynaptic or postsynaptic. Moreover, dopaminergic neurons receive connections from a number of neurons in reciprocal DA cortical-subcortical networks, with different neurotransmitters and neuromodulators, which in turn may modulate neurodegenerative processes. These are just examples that show how to understand the processes addressed here; a wider system perspective is required in humans and preclinical models to reach relevant translational results.

Indeed, imaging and molecular analysis methods may facilitate the discovery of molecular and neurobehavioral biomarkers. In this perspective, $\mathrm{Li}^{+}$proves an extraordinary tool for understanding pathogenic mechanisms and for developing effective therapies.

At the risk of appearing too much "conservative," we do reaffirm the uniqueness of $\mathrm{Li}^{+}$both as a therapeutic agent and as an extraordinary tool in neuroscience research. This is grounded right on its ability to foster, at the same time, neurotransmission and neuroprotection. These properties also unveil that psychiatric and neurological disorders share common dysfunctional molecular mechanisms that can be equally relieved both concerning symptomatic cure and disease-modifying events.

\section{REFERENCES}

1. Diniz BS, Machado-Vieira R, Forlenza OV. Lithium and neuroprotection: translational evidence and implications for the treatment of neuropsychiatry disorders. Neuropsychiatr Dis Treat. 2013;2013:493-500.
2. Forlenza OV, De-Paula VJ, Diniz BS. Neuroprotective effects of lithium: implications for the treatment of Alzheimer's disease and related neurodegenerative disorders. ACS Chem Neurosci. 2014;5:443-50.

3. Baldessarini RJ, Tondo L, Vázquez GH. Pharmacological treatment of adult bipolar disorder. Mol Psychiatry. 2019;24:198-217.

4. Limanaqi F, Biagioni $F$, Ryskalin L, Busceti $C L$, Fornai $F$. Molecular mechanisms linking ALS/FTD and psychiatric disorders, the potential effects of lithium. Front Cell Neurosci. 2019;13:450.

5. Tondo L, Alda $M$, Bauer $M$, Bergink V, Grof $P$, Hajek $T$, et al. Clinical use of lithium salts: guide for users and prescribers. Int J Bipolar Disord. 2019;7:16.

6. Wilson EN, Do Carmo S, lulita MF, Hall H, Ducatenzeiler A, Marks AR, et al. BACE1 inhibition by microdose lithium formulation NP03 rescues memory loss and early stage amyloid neuropathology. Transl Psychiatry. 2017;7:e1190.

7. Ryskalin L, Limanaqi F, Frati A, Busceti $C L$, Fornai F. mTORrelated brain dysfunctions in neuropsychiatric disorders. Int J Mol Sci. 2018;19:E2226.

8. Pasquali L, Busceti CL, Fulceri F, Paparelli A, Fornai F. Intracellular pathways underlying the effects of lithium. Behav Pharmacol. 2010;21:473-92.

9. Jakobsson E, Argüello-Miranda O, Chiu SW, Fazal Z, Kruczek J, Nunez-Corrales S, et al. Towards a unified understanding of lithium action in basic biology and its significance for applied biology. J Membr Biol. 2017;250:587-604.

10. Pisano S, Pozzi M, Catone G, Scrinzi G, Clementi E, Coppola G, et al. Putative mechanisms of action and clinical use of lithium in children and adolescents: a critical review. Curr Neuropharmacol. 2019;17:318-41.

11. Jope RS. Anti-bipolar therapy: mechanism of action of lithium. Mol Psychiatry. 1999;4:117-28.

12. Freland L, Beaulieu JM. Inhibition of GSK3 by lithium, from single molecules to signaling networks. Front Mol Neurosci. 2012;5:14.

13. Ryves WJ, Harwood AJ. Lithium inhibits glycogen synthase kinase-3 by competition for magnesium. Biochem Biophys Res Commun. 2001;280:720-5.

14. Jope RS. Lithium and GSK-3: one inhibitor, two inhibitory actions, multiple outcomes. Trends Pharmacol Sci. 2003;24:441-3.

15. Mendes CT, Mury FB, de Sá Moreira E, Alberto FL, Forlenza OV, Dias-Neto E, et al. Lithium reduces Gsk3b mRNA levels: implications for Alzheimer disease. Eur Arch Psychiatr Clin Neurosci. 2009;259:16-22.

16. Beurel E, Grieco SF, Jope RS. Glycogen synthase kinase-3 (GSK3): regulation, actions, and diseases. Pharmacol Ther. 2015;148:114-31.

17. Piovesan D, Profiti G, Martelli PL, Casadio R. "The human magnesome": detecting magnesium binding sites on human proteins. BMC Bioinformatics. 2012;13:1.

18. Patel S, Yenush L, Rodríguez PL, Serrano R, Blundell TL. Crystal structure of an enzyme displaying both inositol-polyphosphate-1-phosphatase and 3'-phosphoadenosine- $5^{\prime}$-phosphate phosphatase activities: a novel target of lithium therapy. J Mol Biol. 2002;15:677-85.

19. Dutta A, Bhattacharyya S, Dutta D, Das AK. Structural elucidation of the binding site and mode of inhibition of $\mathrm{Li}(+)$ and $\mathrm{Mg}(2+)$ in inositol monophosphatase. FEBS J. 2014;281:5309-24.

20. Dollins DE, Xiong JP, Endo-Streeter S, Anderson DE, Bansal VS, Ponder JW, et al. A structural basis for lithium and substrate binding of an inositide phosphatase. J Biol Chem. 2020;296:1-10.

21. Post RM. Role of BDNF in bipolar and unipolar disorder: clinical and theoretical implications. J Psychiatr Res. 2007;41:979-90.

22. Tunca Z, Ozerdem A, Ceylan D, Yalçın Y, Can G, Resmi H, et al. Alterations in BDNF (brain derived neurotrophic factor) and GDNF (glial cell line-derived neurotrophic factor) serum levels in bipolar disorder: the role of lithium. J Affect Disord. 2014;166:193-200.

23. Nahman S, Belmaker RH, Azab AN. Effects of lithium on lipopolysaccharideinduced inflammation in rat primary glia cells. Innate Immun. 2012;18:447-58.

24. Basselin M, Villacreses NE, Lee HJ, Bell JM, Rapoport SI. Chronic lithium administration attenuates upregulated brain arachidonic acid metabolism in a rat model of neuroinflammation. J Neurochem. 2007;102:761-72.

25. Schwartz M, Kipnis J, Rivest S, Prat A. How do immune cells support and shape the brain in health, disease, and aging? J Neurosci. 2013;33:17587-96.

26. Rashid HO, Yadav RK, Kim HR, Chae HJ. ER stress: autophagy induction, inhibition and selection. Autophagy. 2015;11:1956-77.

27. Yan MM, Ni JD, Song D, Ding M, Huang J. Interplay between unfolded protein response and autophagy promotes tumor drug resistance. Oncol Lett. 2015;10:1959-69.

28. Fornai F, Longone $\mathrm{P}$, Cafaro L, Kastsiuchenka O, Ferrucci M, Manca ML, et al. Lithium delays progression of amyotrophic lateral sclerosis. Proc Natl Acad Sci USA. 2008;105:2052-7.

29. van Eijk R, Jones AR, Sproviero W, Shatunov A, Shaw PJ, Leigh PN, et al. Metaanalysis of pharmacogenetic interactions in amyotrophic lateral sclerosis clinical trials. Neurology. 2017;89:1915-22. 
30. Xie $Y$, Zhou B, Lin MY, Sheng ZH. Progressive endolysosomal deficits impair autophagic clearance beginning at early asymptomatic stages in fALS mice. Autophagy. 2015;11:1934-6.

31. Lee JK, Shin JH, Lee JE, Choi EJ. Role of autophagy in the pathogenesis of amyotrophic lateral sclerosis. Biochim Biophys Acta. 2015;1852:2517-24.

32. Wang SY, Ren $M$, Jiang $H Z$, Wang J, Jiang $H Q$, Yin $X$, et al. Notch pathway is activated in cell culture and mouse models of mutant SOD1-related familial amyotrophic lateral sclerosis, with suppression of its activation as an additional mechanism of neuroprotection for lithium and valproate. Neuroscience. 2015;301:276-88.

33. Merenlender-Wagner A, Malishkevich A, Shemer Z, Udawela M, Gibbons A, Scarr $E$, et al. Autophagy has a key role in the pathophysiology of schizophrenia. Mol Psychiatry. 2015;20:126-32.

34. Natale G, Lenzi P, Lazzeri G, Falleni A, Biagioni F, Ryskalin L, et al. Compartmentdependent mitochondrial alterations in experimental ALS, the effects of mitophagy and mitochondriogenesis. Front Cell Neurosci. 2015;9:434.

35. Kim Y, Santos R, Gage FH, Marchetto MC. Molecular mechanisms of bipolar disorder: progress made and future challenges. Front Cell Neurosci. 2017;11:30.

36. Tooze SA, Schiavo G. Liaisons dangereuses: autophagy, neuronal survival and neurodegeneration. Curr Opin Neurobiol. 2008;18:504-15.

37. Okamoto K. Organellophagy: eliminating cellular building blocks via selective autophagy. J Cell Biol. 2014;205:435-45.

38. Nixon RA, Wegiel J, Kumar A, Yu WH, Peterhoff C, Cataldo A, et al. Extensive involvement of autophagy in Alzheimer disease: an immuno-electron microscopy study. J Neuropathol Exp Neurol. 2005;64:113-22.

39. Nixon RA. The role of autophagy in neurodegenerative disease. Nat Med. 2013;19:983-97.

40. Barker RA, Fujimaki M, Rogers $P$, Rubinsztein DC. Huntingtin-lowering strategies for Huntington's disease. Expert Opin Investig Drugs. 2020;29:1125-32.

41. Weikel KA, Cacicedo JM, Ruderman NB, Ido Y. Knockdown of GSK3 $\beta$ increases basal autophagy and AMPK signalling in nutrient-laden human aortic endothelial cells. Biosci Rep. 2016;36:e00382.

42. Chiu CT, Wang Z, Hunsberger JG, Chuang DM. Therapeutic potential of mood stabilizers lithium and valproic acid: beyond bipolar disorder. Pharmacol Rev. 2013;65:105-42.

43. Limanaqi F, Biagioni F, Busceti CL, Ryskalin L, Soldani P, Frati A, et al. Cell clearing systems bridging neuro-immunity and synaptic plasticity. Int J Mol Sci. 2019;20:2197.

44. Sarkar S, Rubinsztein DC. Inositol and IP3 levels regulate autophagy: biology and therapeutic speculations. Autophagy. 2006;2:132-4.

45. Motoi Y, Shimada K, Ishiguro K, Hattori N. Lithium and autophagy. ACS Chem Neurosci. 2014;5:434-42.

46. Shimada K, Motoi Y, Ishiguro K, Kambe T, Matsumoto SE, Itaya M, et al. Longterm oral lithium treatment attenuates motor disturbance in tauopathy model mice: implications of autophagy promotion. Neurobiol Dis. 2012;46:101-8.

47. Struewing IT, Barnett CD, Tang T, Mao CD. Lithium increases PGC-1alpha expression and mitochondrial biogenesis in primary bovine aortic endothelial cells. FEBS J. 2007;274:2749-65.

48. Wang JF. Defects of mitochondrial electron transport chain in bipolar disorder: implications for mood-stabilizing. Can J Psychiatry. 2007;52:753-62.

49. Bar-Yosef T, Damri O, Agam G. Dual role of autophagy in diseases of the central nervous system. Front Cell Neurosci. 2019;28:196.

50. Kim SH, Park S, Yu HS, Ko KH, Park HG, Kim YS. The antipsychotic agent clozapine induces autophagy via the AMPK-ULK1-Beclin1 signaling pathway in the rat frontal cortex. Prog Neuropsychopharmacol Biol Psychiatry. 2018;81:96-104.

51. Hao L, Ben-David O, Babb SM, Futerman AH, Cohen BM, Buttner EA. Clozapine modulates glucosylceramide, clears aggregated proteins, and enhances ATG8/ LC3 in Caenorhabditis elegans. Neuropsychopharmacology. 2017;42:951-62.

52. Kinzler MN, Zielke S, Kardo S, Meyer N, Kögel D, van Wijk S, et al. STF-62247 and pimozide induce autophagy and autophagic cell death in mouse embryonic fibroblasts. Sci Rep. 2020;10:1-15.

53. Kessing LV, Forman JL, Andersen PK. Does lithium protect against dementia? Bipolar Disord. 2010;12:87-94.

54. Nunes PV, Forlenza OV, Gattaz WF. Lithium and risk for Alzheimer's disease in elderly patients with bipolar disorder. Br J Psychiatr. 2007;190:359-60.

55. Matsunaga $S$, Kishi $T$, Annas $P$, Basun $H$, Hampel $H$, Iwata $N$. Lithium as a treatment for Alzheimer's disease: a systematic review and meta-analysis. J Alzheimers Dis. 2015;48:403-10.

56. Forlenza OV, Torres CA, Talib LL, de Paula VJ, Joaquim HP, Diniz BS, et al. Increased platelet GSK3B activity in patients with mild cognitive impairment and Alzheimer's disease. J Psychiatr Res. 2011;45:220-4.

57. Phiel CJ, Wilson CA, Lee VM, Klein PS. GSK-3alpha regulates production of Alzheimer's disease amyloid- $\beta$ peptides. Nature. 2003;423:435-9.

58. Tramutola A, Triplett JC, Di Domenico F, Niedowicz DM, Murphy MP, Coccia R, et al. Alteration of mTOR signaling occurs early in the progression of Alzheimer disease $(A D)$ : analysis of brain from subjects with pre-clinical $A D$, amnestic mild cognitive impairment and late-stage AD. J Neurochem. 2015;133:739-49.

59. Lim YY, Villemagne VL, Laws SM, Pietrzak RH, Snyder PJ, Ames D, et al. APOE and BDNF polymorphisms moderate amyloid $\beta$-related cognitive decline in preclinical Alzheimer's disease. Mol Psychiatry. 2015;20:1322-8.

60. Nigam SM, Xu S, Kritikou JS, Marosi K, Brodin L, Mattson MP. Exercise and BDNF reduce $A \beta$ production by enhancing a-secretase processing of APP. J Neurochem. 2017;142:286-96.

61. Wurzelmann M, Romeika J, Sun D. Therapeutic potential of brain-derived neurotrophic factor (BDNF) and a small molecular mimics of BDNF for traumatic brain injury. Neural Regen Res. 2017;12:7-12.

62. Zhang Z, Liu X, Schroeder JP, Chan CB, Song M, Yu SP, et al. 7,8-Dihydroxyflavone prevents synaptic loss and memory deficits in a mouse model of Alzheimer's disease. Neuropsychopharmacology. 2014;39:638-50.

63. Budni J, Feijó DP, Batista-Silva H, Garcez ML, Mina F, Belletini-Santos T, et al. Lithium and memantine improve spatial memory impairment and neuroinflammation induced by $\beta$-amyloid 1-42 oligomers in rats. Neurobiol Learn Mem. 2017;141:84-92.

64. Kim G, Gautier O, Tassoni-Tsuchida E, Ma XR, Gitler AD. ALS genetics: gains, losses, and implications for future therapies. Neuron. 2020;108:822-42.

65. Ittner LM, Halliday GM, Kril JJ, Götz J, Hodges JR, Kiernan MC. ALS-translating mouse studies into clinical trials. Nat Rev Neurol. 2015;11:360-6.

66. Fornai F, Longone $P$, Ferrucci M, Lenzi $P$, Isidoro C, Ruggieri S, et al. Autophagy and amyotrophic lateral sclerosis: the multiple roles of lithium. Autophagy. 2008;4:527-30.

67. Malhi GS, Tanious M, Das P, Coulston CM, Berk M. Potential mechanisms of action of lithium in bipolar disorder. Current understanding. CNS Drugs. 2013;27:135-53.

68. Toker L, Agam G. Lithium, inositol and mitochondria. ACS Chem Neurosci. 2014;5:411-2.

69. Pasquali L, Longone P, Isidoro C, Ruggieri S, Paparelli A, Fornai F. Autophagy, lithium, and amyotrophic lateral sclerosis. Muscle Nerve. 2009;40:173-94.

70. Ramesh N, Pandey UB. Autophagy dysregulation in ALS: when protein aggregates get out of hand. Front Mol Neurosci. 2017;10:263.

71. Deng Z, Lim J, Wang Q, Purtell K, Wu S, Palomo GM, et al. ALS-FTLD-linked mutations of SQSTM1/p62 disrupt selective autophagy and NFE2L2/NRF2 antioxidative stress pathway. Autophagy. 2019;30:1-15.

72. Breen MS, White $\mathrm{CH}$, Shekhtman $\mathrm{T}$, Lin $\mathrm{K}$, Looney $\mathrm{D}$, Woelk $\mathrm{CH}$, et al. Lithiumresponsive genes and gene networks in bipolar disorder patient-derived lymphoblastoid cell lines. Pharmacogenomics J. 2016;16:446-53.

73. Prosser JM, Fieve RR. Patients receiving lithium therapy have a reduced prevalence of neurological and cardiovascular disorders. Prog Neuropsychopharmacol Biol Psychiatry. 2016;71:39-44.

74. Lieu CA, Dewey CM, Chinta SJ, Rane A, Rajagopalan S, Batir S, et al. Lithium prevents parkinsonian behavioral and striatal phenotypes in an aged parkin mutant transgenic mouse model. Brain Res. 2014;1591:111-7.

75. Beaulieu JM, Gainetdinov RR, Caron MG. Akt/GSK3 signaling in the action of psychotropic drugs. Annu Rev Pharmacol Toxicol. 2009;49:327-47.

76. Spillantini MG, Schmidt ML, Lee VM, Trojanowski JQ, Jakes R, Goedert M. Alphasynuclein in Lewy bodies. Nature. 1997;388:839-40.

77. Roberts RF, Wade-Martins R, Alegre-Abarrategui J. Direct visualization of alphasynuclein oligomers reveals previously undetected pathology in Parkinson's disease brain. Brain. 2015;138:1642-57.

78. Sato S, Hattori N. Dopaminergic neuron-specific autophagy-deficient mice. dopaminergic neuron-specific autophagy-deficient mice. Methods Mol Biol. 2018;759:173-5.

79. Abou-Saleh MT, Müller-Oerlinghausen B, Coppen AJ. Lithium in the episode and suicide prophylaxis and in augmenting strategies in patients with unipolar depression. Int J Bipolar Disord. 2017;5:11

80. Undurraga J, Sim K, Tondo L, Gorodischer A, Azua E, Tay KH, et al. Lithium treatment for unipolar major depressive disorder: systematic review. J Psychopharmacol. 2019;33:167-76.

81. McIntyre RS. Implementing appropriate treatment strategies for varying types of depression. J Clin Psychiatry. 2016;77:e1355.

82. Bauer M, Adli M, Ricken R, Severus E, Pilhatsch M. Role of lithium augmentation in the management of major depressive disorder. CNS Drugs. 2014;28:331-42.

83. Guzzetta F, Tondo L, Centorrino F, Baldessarini RJ. Lithium treatment reduces suicide risk in recurrent major depressive disorder. J Clin Psychiatry. 2007;68:380-3.

84. Miczek KA, Fish EW, De Bold JF, De Almeida RM. Social and neural determinants of aggressive behavior: pharmacotherapeutic targets at serotonin, dopamine and gamma-aminobutyric acid systems. Psychopharmacology. 2002;163:434-58.

85. Beurel E, Jope RS. Inflammation and lithium: clues to mechanisms contributing to suicide-linked traits. Transl Psychiatry. 2014;4:e488.

86. Hayes DJ, Jupp B, Sawiak SJ, Merlo E, Caprioli D, Dalley JW. Brain Y-aminobutyric acid: a neglected role in impulsivity. Eur J Neurosci. 2014;39:1921-32. 
87. Hui KK, Tanaka M. Autophagy links MTOR and GABA signaling in the brain. Autophagy. 2019;15:1848-9.

88. Zink M, Englisch S, Meyer-Lindenberg A. Polypharmacy in schizophrenia. Curr Opin Psychiatry. 2010;23:103-11.

89. Aydin M, Ilhan BC, Calisir S, Yildirim S, Eren I. Continuing clozapine treatment with lithium in schizophrenic patients with neutropenia or leukopenia: brief review of literature with case reports. Ther Adv Psychopharmacol. 2016;6:33-8.

90. Rybakowski JK. 120th Anniversary of the Kraepelinian Dichotomy of Psychiatric Disorders. Curr Psychiatry Rep. 2019;21:65.

91. Lichtenstein P, Yip BH, Björk C, Pawitan Y, Cannon TD, Sullivan PF, et al. Common genetic determinants of schizophrenia and bipolar disorder in Swedish families: a population-based study. Lancet. 2009;373:234-9.

92. Selzam S, Coleman JRI, Caspi A, Moffitt TE, Plomin R. A polygenic $p$ factor for major psychiatric disorders. Transl Psychiatry. 2018;8:1-9.

93. Gordovez FJA, McMahon FJ. The genetics of bipolar disorder. Mol Psychiatry. 2020;25:544-59.

94. Leucht S, Helfer B, Dold M, Kissling W, McGrath JJ. Lithium for schizophrenia. Cochrane Database Syst Rev. 2015;2015:CD003834.

95. Wang Y, Xia J, Helfer B, Li C, Leucht S. Valproate for schizophrenia. Cochrane Database Syst Rev. 2016;11:CD004028.

96. Ago Y, Tanaka T, Kita Y, Tokumoto H, Takuma K, Matsuda T. Lithium attenuates methamphetamine-induced hyperlocomotion and behavioral sensitization via modulation of prefrontal monoamine release. Neuropharmacology. 2012;62:1634-9.

97. Post RM. Epigenetic basis of sensitization to stress, affective episodes, and stimulants: implications for illness progression and prevention. Bipolar Disord. 2016;18:315-24.

98. Weidenauer A, Bauer M, Sauerzopf U, Bartova L, Praschak-Rieder N, Sitte $\mathrm{HH}_{\text {, }}$ et al. Making sense of: sensitization in schizophrenia. Int J Neuropsychopharmacol. 2016;20:1-10.

99. Valvassori SS, Mariot E, Varela RB, Bavaresco DV, Dal-Pont GC, Ferreira CL, et al. The role of neurotrophic factors in manic-, anxious- and depressive-like behaviors induced by amphetamine sensitization: implications to the animal model of bipolar disorder. J Affect Disord. 2019;245:1106-13.

100. Da Costa SC, Passos IC, Lowri C, Soares JC, Kapczinski F. Refractory bipolar disorder and neuroprogression. Prog Neuropsychopharmacol Biol Psychiatry. 2016;70:103-10.

101. Badiani A, Cabib S, Puglisi-Allegra S. Chronic stress induces strain- dependent sensitization to the behavioral effects of amphetamine in the mouse. Pharmacol Biochem Behav. 1992;43:53-60.

102. Cabib S. Strain-dependent behavioural sensitization to amphetamine: role of environmental influences. Behav Pharmacol. 1993;4:367-74.

103. Valvassori SS, Tonin PT, Varela RB, Carvalho AF, Mariot E, Amboni RT, et al. Lithium modulates the production of peripheral and cerebral cytokines in an animal model of mania induced by dextroamphetamine. Bipolar Disord. 2015;17:507-17.

104. Antelman SM, Eichler AJ, Black CA, Kocan D. Interchangeability of stress and amphetamine in sensitization. Science. 1980;207:329-31.

105. Cabib S, Puglisi-Allegra S. The mesoaccumbens dopamine in coping with stress. Neurosci Biobehav Rev. 2012;36:79-89.

106. Douma EH, de Kloet ER. Stress-induced plasticity and functioning of ventral tegmental dopamine neurons. Neurosci Biobehav Rev. 2019;108:48-77.

107. Strakowski SM, Sax KW. Progressive behavioral response to repeated D amphetamine challenge: further evidence for sensitization in humans. Biol Psychiatry. 1998;44:1171-7.

108. Cuesta S, Severin MJ, Batuecas J, Rosso SB, Pacchioni AM. Wnt/beta- catenin pathway in the prefrontal cortex is required for cocaine-induced neuroadaptations. Addict Biol. 2016;22:933-45.

109. Cuesta S, Batuecas J, Severin MJ, Funes A, Rosso SB, Pacchioni AM. Role of Wnt/ $\beta$-catenin pathway in the nucleus accumbens in long-term cocaine-induced neuroplasticity: a possible novel target for addiction treatment. J Neurochem. 2017;140:114-25.

110. Xu CM, Wang J, Wu P, Zhu WL, Li QQ, Xue YX, et al. Glycogen synthase kinase 3beta in the nucleus accumbens core mediates cocaine-induced behavioral sensitization. J Neurochem. 2009;111:1357-68.

111. Laruelle M, Abi-Dargham A, Gil R, Kegeles L, Innis R. Increased dopamine transmission in schizophrenia: relationship to illness phases. Biol Psychiatry. 1999;46:56-72.

112. Dean B. Neurochemistry of schizophrenia: the contribution of neuroimaging postmortem pathology and neurochemistry in schizophrenia. Curr Top Med Chem. 2012:12:2375-92.

113. Howes OD, Kambeitz J, Kim E, Stahl D, Slifstein M, Abi-Dargham A, et al. The nature of dopamine dysfunction in schizophrenia and what this means for treatment. Arch Gen Psychiatry. 2012;69:776-86.
114. Limanaqi F, Gambardella S, Biagioni F, Busceti C, Fornai F. Epigenetic effects induced by methamphetamine and methamphetamine-dependent oxidative stress. Oxid Med Cell Longev. 2018;2018:1-28.

115. Perreault ML, Hasbi A, Alijaniaram M, Fan T, Varghese G, Fletcher PJ, et al. The dopamine D1-D2 receptor heteromer localizes in dynorphin/enkephalin neurons: increased high affinity state following amphetamine and in schizophrenia. J Biol Chem. 2010;285:36625-34.

116. Wang D, Ji X, Liu J, Li Z, Zhang X. Dopamine receptor subtypes differentially regulate autophagy. Int J Mol Sci. 2018;19:1540.

117. Fornai F, Lenzi $P$, Gesi M, Ferrucci M, Lazzeri G, Capobianco L, et al. Similarities between methamphetamine toxicity and proteasome inhibition. Ann NY Acad Sci. 2004;1025:162-70.

118. Lazzeri G, Lenzi $P$, Gesi $M$, Ferrucci $M$, Fulceri $F$, Ruggieri $S$, et al. In PC12 cells neurotoxicity induced by methamphetamine is related to proteasome inhibition. Ann NY Acad Sci. 2006;1074:174-7.

119. Moszczynska A, Yamamoto BK. Methamphetamine oxidatively damages parkin anddecreases the activity of $26 \mathrm{~S}$ proteasome in vivo. J Neurochem. 2011;116:1005-17.

120. Ferrucci $M$, Ryskalin L, Biagioni F, Gambardella $S$, Busceti $C L$, Falleni $A$, et al. Methamphetamine increases prion protein and induces dopamine-dependent expression of protease resistant PrPsc. Arch Ital Biol. 2017;155:81-97.

121. Lazzeri G, Biagioni F, Fulceri F, Busceti CL, Scavuzzo MC, Ippolito C, et al. mTOR modulates methamphetamine-induced toxicity through cell clearing systems. Oxid Med Cell Longev. 2018;2018:6124745.

122. Limanaqi F, Biagioni F, Busceti $C L$, Ryskalin L, Fornai $F$. The effects of proteasome on baseline and methamphetamine-dependent dopamine transmission. Neurosci Biobehav Rev. 2019;102:308-17.

123. Beaulieu JM, Sotnikova TD, Yao WD, Kockeritz L, Woodgett JR, Gainetdinov RR, et al. Lithium antagonizes dopamine-dependent behaviors mediated by an AKT/glycogen synthase kinase 3 signaling cascade. Proc Natl Acad Sci USA. 2004;101:5099-104.

124. Beaulieu JM, Caron MG. Beta-arrestin goes nuclear. Cell. 2005;123:755-7.

125. Beaulieu JM, Sotnikova TD, Marion S, Lefkowitz RJ, Gainetdinov RR, Caron MG. An Akt/beta-arrestin 2/PP2A signaling complex mediates dopaminergic neurotransmission and behavior. Cell. 2005;122:261-73.

126. Beaulieu JM, Gainetdinov RR. The physiology, signaling, and pharmacology of dopamine receptors. Pharmacol Rev. 2011;63:182-217.

127. Beaulieu JM, Marion S, Rodriguiz RM, Medvedev IO, Sotnikova TD, Ghisi V, et al. A beta-arrestin 2 signaling complex mediates lithium action on behavior. Cell. 2008;132:125-36.

128. Beaulieu JM, Gainetdinov RR, Caron MG. The Akt-GSK-3 signaling cascade in the actions of dopamine. Trends Pharmacol Sci. 2007;28:166-72.

129. Beaulieu JM, Tirotta E, Sotnikova TD, Masri B, Salahpour A, Gainetdinov RR, et al. Regulation of Akt signaling by D2 and D3 dopamine receptors in vivo. J Neurosci. 2007;27:881-5.

130. Perreault ML, Hasbi A, O'Dowd BF, George SR. Heteromeric dopamine receptor signaling complexes: emerging neurobiology and disease relevance. Neuropsychopharmacology. 2014;39:156-68.

131. Beaulieu JM, Espinoza S, Gainetdinov R,R. Dopamine receptors - IUPHAR Review 13. Br J Pharmacol. 2015;172:1-23.

132. Gitlin M, Malhi GS. The existential crisis of bipolar II disorder. Int J Bipolar Disord. 2020;8:5.

133. Mertens J, Wang QW, Kim Y, Yu DX, Pham S, Yang B, et al. Differential responses to lithium in hyperexcitable neurons from patients with bipolar disorder. Nature. 2015;527:95-9.

134. Ashok AH, Marques TR, Jauhar S, Nour MM, Goodwin GM, Young AH, et al. The dopamine hypothesis of bipolar affective disorder: the state of the art and implications for treatment. Mol Psychiatry. 2017;22:666-79.

135. Laruelle $M$. The role of endogenous sensitization in the pathophysiology of schizophrenia: implications from recent brain imaging studies. Brain Res Brain Res Rev. 2000;31:371-84.

136. Pathak G, Ibrahim BA, McCarthy SA, Baker K, Kelly MP. Amphetamine sensitization in mice is sufficient to produce both manic- and depressive-related behaviors as well as changes in the functional connectivity of corticolimbic structures. Neuropharmacology. 2015;95:434-47.

137. Volman I, Pringle A, Verhagen L, Browning M, Cowen PJ, Harmer CJ. Lithium modulates striatal reward anticipation and prediction error coding in healthy volunteers. Neuropsychopharmacology. 2021;46:386-93.

138. Koukopoulos, A. The primacy of mania. In: Bipolar psychopharmacotherapy: caring for the patient. In: Akiskal, HS, Tohen, M, eds. Hoboken, NJ: John Wiley and Sons; 2006. p. 169-91.

139. Sani G, Simonetti A, Reginaldi D, Koukopoulos AE, Del Casale A, Manfredi G, et al. Free interval duration: clinical evidence of the primary role of excitement in bipolar disorder. Curr Neuropharmacol. 2017;15:394-401.

140. Sani G, Fiorillo A. The use of lithium in mixed states. CNS Spectr. 2019;28:1-3. 
10

141. Ventura R, Cabib S, Alcaro A, Orsini C, Puglisi-Allegra S. Norepinephrine in the prefrontal cortex is critical for amphetamine-induced reward and mesoaccumbens dopamine release. J Neurosci. 2003;23:1879-85.

142. Schank JR, Ventura R, Puglisi-Allegra S, Alcaro A, Cole CD, Liles LC, et al. Dopamine beta-hydroxylase knockout mice have alterations in dopamine signaling and are hypersensitive to cocaine. Neuropsychopharmacology. 2006;31:2221-30.

143. Tassin JP. Uncoupling between noradrenergic and serotonergic neurons as a molecular basis of stable changes in behavior induced by repeated drugs of abuse. Biochem Pharmacol. 2008;75:85-97.

144. Jope RS. A bimodal model of the mechanism of action of lithium. Mol Psychiatry. 1999;4:21-5.

145. Jope RS. Anti-bipolar therapy: mechanism of action of lithium. Mol Psychiatry. 1999;4:117-28.

146. Ellison-Wright I, Bullmore E. Anatomy of bipolar disorder and schizophrenia:a meta-analysis. Schizophr Res. 2010;117:1-12.

147. Henstridge CM, Hyman BT, Spires-Jones TL. Beyond the neuron-cellular interactions early in Alzheimer disease pathogenesis. Nat Rev Neurosci. 2019;20:94-108.

148. Frangou S. A systems neuroscience perspective of schizophrenia and bipolar disorder. Schizophr Bull. 2014;40:523-31.

\section{ACKNOWLEDGEMENTS}

This research was funded by the Italian Ministry of Health, "Ricerca Corrente 2020-2021. and Grant Cinque per Mille to IRCCS Neuromed".

\section{COMPETING INTERESTS}

The authors declare no competing interests.

\section{ADDITIONAL INFORMATION}

Correspondence and requests for materials should be addressed to S.P-A. or F.F.

Reprints and permission information is available at http://www.nature.com/reprints

Publisher's note Springer Nature remains neutral with regard to jurisdictional claims in published maps and institutional affiliations.

(i) Open Access This article is licensed under a Creative Commons Attribution 4.0 International License, which permits use, sharing, adaptation, distribution and reproduction in any medium or format, as long as you give appropriate credit to the original author(s) and the source, provide a link to the Creative Commons license, and indicate if changes were made. The images or other third party material in this article are included in the article's Creative Commons license, unless indicated otherwise in a credit line to the material. If material is not included in the article's Creative Commons license and your intended use is not permitted by statutory regulation or exceeds the permitted use, you will need to obtain permission directly from the copyright holder. To view a copy of this license, visit http://creativecommons. org/licenses/by/4.0/.

(c) The Author(s) 2021 